\title{
Children's Reading of Text on Interactive Whiteboards
}

\author{
Nicholas Vanderschantz \\ Computer Science Department \\ University of Waikato \\ Hamilton, New Zealand \\ vtwoz@waikato.ac.nz
}

\author{
Claire Timpany \\ Computer Science Department \\ University of Waikato \\ Hamilton, New Zealand \\ ctimpany@waikato.ac.nz
}

\author{
Ana Hill \\ Computer Science Department \\ University of Waikato \\ Hamilton, New Zealand
}

\begin{abstract}
The development and adoption of technology for the classroom is changing the way education is delivered and perceived by students. The availability of Interactive Whiteboard (IWB) technology in New Zealand classrooms is increasing. With this change in technology comes a change in the way educational resource material is presented to students. Significantly, there is a paucity of scholarly research regarding the presentation of typographic information that is efficient and effective for children's' reading and learning on screen. This research assisted in gaining an overview of the types of material and resources being used on IWB in New Zealand classrooms and the quality, readability and legibility of the typographic content of this material. This paper seeks to propose cursory considerations for typographic presentation on IWB as discovered through both interviews with students and the observations of the researcher. This experiment seeks to identify whether typographic factors are being used effectively when displaying text for children's reading on IWB's and to investigate children's preferences and issues with typographic elements.
\end{abstract}

\section{Author Keywords \\ interactive whiteboards, IWB, on-screen reading, typography, contemporary ICT}

\section{ACM Classification Keywords}

H5.2. Information interfaces and presentation (e.g., HCI): Screen design (e.g., text, graphics, color), User-centered design.

\section{BACKGROUND}

Interactive Whiteboards (IWB) are one of many digital technologies being introduced into classrooms, however, there is currently little significant literature investigating children's reading from these IWB. It is clear that the flexibility of the IWB has given teachers and other users of this medium the freedom to incorporate contemporary ICT based teaching resource material into the classroom with ease. In a growing number of classrooms worldwide traditional blackboard and whiteboard are being replaced with these interactive displays and this is allowing for new forms of interactivity in learning as well as the use of evolved resource material. Some of the common resource material being displayed and used on these large screens includes large amounts of static text and image, moving text and image, and the inclusion of interactive and gamelike learning tools all through this single device.

This study was developed to understand the current situation with regards to presentation of, and children's perceptions of, reading on IWB. Through expert observation followed by semi-structured interviews, this paper attempts to identify if improvement can be made to the readability and legibility of resource material being used on IWB's within New Zealand schools and recommend how this might be achieved. This insight will prove useful in assisting with the future development of quality material for IWB, which ensures readability and legibility, while meeting the aesthetic requirements of the students viewing this material.

\section{RELATED WORK}

The related work in this area sits in investigations of IWB and their use within the classroom to date as well as research pertaining to reading from a distance and text presentation for children's reading.

Research regarding IWB to date has predominantly focused on observing the interactive and educational benefits of the boards, as well as exploring how the dynamic benefits of the boards can be best utilised in these educational settings (Beeland, 2002; Moseley et al., 1999). While much has been discussed in regards to installation, use and lesson design of materials for IWB, little research has been conducted to investigate what entails good reading practice from an IWB for children, or what typographic factors influence children's reading from these devices. One of the few investigations to consider this area was that of Moss et al. (2007) who suggested that teachers have limited design knowledge when it comes to creating resource material for the IWB and posited that reading may suffer as a result.

Interactive Whiteboards have broadened the range of resources that teachers can utilise in the classroom, but the way that these resources are presented on these large screens, especially written words, requires careful consideration for successful reading and comprehension by the students. Reading is a key activity in the regular use of these IWB in the classroom and is a vital element of classroom learning. It is clear from the reading science, $\mathrm{HCI}$, printing, graphic design and psychology literature that reading can be hindered by the inefficient and ineffective use of typographic presentation (typography) (Burt, 1959; Dillon, 2004; Morison, 1936; Tinker, 1963; Walker \& Reynolds, 2000; Watts \& Nisbet, 1974). Typographic factors have a significant influence on how information is presented to children, through this and other media, affecting their ability to read it. 
There are a number of factors that play an important role in children's reading. Typographic features include the size, form, thickness and weight of individual letterforms and glyphs, as well as the length of line, and the letter-, word- and line-spacing. Additionally, the text colour, background colour, and positioning of supporting illustration all impact the successful and efficient reading of text (Huey, 1908; Legge, Pelli, Rubin, \& Schleske, 1985; Rayner, 1998). Hierarchy of presentation text is also of consideration in children's reading. Hierarchy is described by Lupton as an "organisational system for content" that helps readers "scan a text, knowing where to enter and exit and how to pick and choose among its offerings" (Lupton, 2004, p. 94). It is clear that reading paths created through hierarchy and consideration of how a child should read a document when reading at a distance and on an IWB will become a factor in a child's success with the use of these tools.

Unique to this study are the conditions of typographic presentation and display of large text and reading from a distance from an IWB and how children perceive these factors as impacting their reading and learning experiences. $6 / 6$ or $20 / 20$ vision refers to the distance at which 'normal' sight is identified. "The numerator refers to the maximum distance at which the letter is viewed (typically $6 \mathrm{~m}$ or $20 \mathrm{ft}$ ), and the denominator refers to the maximum distance at which the individual can successfully identify the letters" (Lupton, 2004, p. 94). With studies of children's reading from a distance using 'big books', Hughes \& Wilkins found in normal sighted children that the fluency of reading texts smaller in $\mathrm{x}$ height with larger spacing was equal to or better than texts with a larger point size. The National Literacy Strategy recommends a reading distance of $15 \mathrm{ft}(4.75 \mathrm{~m})$, while Hughes et al. recommend a reduction to $10 \mathrm{ft}(3 \mathrm{~m})$ as the maximum distance for children ages 6-8years.

\section{METHOD}

This research identified current typographic presentation conditions on Interactive Whiteboards in New Zealand middle school classrooms, and sought to understand children's preferences and experiences of these conditions. This was achieved through a two-stage methodology constructed by way of user (class in progress) observation, followed by participant (student) semi-structured interview.

The observations and interviews took place at a publicly funded middle school in Hamilton, New Zealand. This school has regular observers and researchers and thus visitors to the classroom are a non-disruptive occurrence for students and teachers. Observations took place from the back of each classroom to give an overview of how the IWB is perceived from the greatest distance within the room. This provided a general understanding of the visual output of the IWB, and gave insight as to how teachers designed, produced and displayed textural material for the IWB. Other factors (controllable/uncontrollable) that contributed to increased or decreased readability or legibility of the resources used on the IWB were also noted. These included room lighting, weather conditions and board position.
Five lessons were observed, occurring at differing times during the school day and over a single school week, each chosen because the IWB was a key aspect of the lesson. IWBs were not observed to be used for the entire length of a class, which at this school were one hour and twenty minutes long. Instead IWB's were used at the beginning of each lesson for between 5 and 20 minutes, and in the case of Observations $1 \& 2$ the final slide remained viewable for students throughout the remainder of the lesson. The content of the lesson and the curriculum covered was selected by the deputy principal without input by the researchers and covered a wide gamut of the New Zealand Middle School curriculum. The annotations made during the observations focused on the typographic elements displayed on the IWB and has garnered an overview of how typographic factors are treated. Specific typefaces, sizes and colour values have not been recorded due to the nature of text legibility. The legibility of a specific typeface, at a specific size would only be measurable at a specific distance and for this study was not practical. The perception of legibility from the point of view of the researcher (a qualified graphic designer) is discussed, as are the perceptions of the students who viewed this material. The boards being used in the observed lessons have a 78-inch interactive surface, with the projector having a resolution of $1024 \times 768$. The brand of IWB used by this school is not seen to have an effect on this experiment and is thus not named within this paper.

The interview process consisted of a series of 14 questions relating to the lesson previously observed, taking approximately 5 minutes per interview to complete. The interview questions set out to identify children's opinions and perceptions of text layout on IWB. The interviews also sought to investigate if student preference of typographic treatments existed. 17 students were interviewed, three from each of Observations 1, 2, $\& 4$ and four from each of Observations $3 \& 5$. Six female and eleven male students were given parental permission to take part in the study.

\section{OBSERVATIONS}

Observation 1 (refer to Table 1 on following page):

Year 8 Music, Early Morning, Overcast

\section{Observation 1 Classroom layout/use:}

The IWB was positioned as the main focal point in the room with a mat ${ }^{1}$ area in front of the board that was able to comfortably accommodate the entire class. The teacher's desk was positioned next to the IWB. The light above the IWB was disconnected to ensure no light shone on the display and impacted clarity of presentation. There were a limited number of windows in the room and no direct sunlight was in contact with the board at this time of the day. Class began with students sitting on the mat in a semi-circle facing the teacher who was next to the IWB.

\footnotetext{
${ }^{1}$ The "mat" in a New Zealand classroom is the colloquially referred to clear space on the floor where the students and teacher regularly gather as a whole class or in small groups for interactive, oral and visual teaching and learning away from the formalities of a desk. This may be referred to as mat time or circle time in the literature.
} 
After the first four slides had been discussed the students moved to the Electric Keyboards further back in the room to practice what they had learned with Slide 5 as a reference on the IWB.

\section{Observation 1 Resource:}

5 slide flipbook ${ }^{2}$

\begin{tabular}{|c|c|c|c|}
\hline & & $\begin{array}{l}\text { Heading font } \\
\text { (text/background) }\end{array}$ & $\begin{array}{l}\text { Body font } \\
\text { (text/background) }\end{array}$ \\
\hline \multirow{3}{*}{ 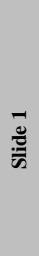 } & Col 1 & - & $\begin{array}{l}\text { Display } \\
\text { (black/lime green) }\end{array}$ \\
\hline & Col 2 & - & $\begin{array}{l}\text { Display } \\
\text { (lime green/80\% grey) }\end{array}$ \\
\hline & Col 3 & $\begin{array}{l}\text { Display } \\
\text { (lime green/40\% grey) }\end{array}$ & $\begin{array}{l}\text { Display Italics } \\
\text { (black/40\% grey) }\end{array}$ \\
\hline 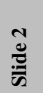 & Col 1 & $\begin{array}{l}\text { 3D text gradient, } \\
\text { drop shadow } \\
\text { (black/white) }\end{array}$ & - \\
\hline \multirow{2}{*}{ कृ } & Row 1 & $\begin{array}{l}\text { Text } \\
\text { (black/white) }\end{array}$ & $\begin{array}{l}\text { Text Bold Weight } \\
\text { (black/white) }\end{array}$ \\
\hline & Row 2 & $\begin{array}{l}\text { Text } \\
\text { (black/white) }\end{array}$ & $\begin{array}{l}\text { Text } \\
\text { (black/white) }\end{array}$ \\
\hline \multirow{2}{*}{ एँ } & Row 1 & $\begin{array}{l}\text { Text } \\
\text { (black/white) }\end{array}$ & $\begin{array}{l}\text { Text Bold Weight } \\
\text { (black/white) }\end{array}$ \\
\hline & Row 2 & $\begin{array}{l}\text { Text } \\
\text { (black/white) }\end{array}$ & $\begin{array}{l}\text { Text } \\
\text { (black/white) }\end{array}$ \\
\hline 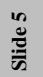 & Col 1 & $\begin{array}{l}\text { Display } \\
\text { (black/no col bg) }\end{array}$ & - \\
\hline
\end{tabular}

Table 1: Typographic Features of Observation 1

This flipbook contained multiple typefaces many of which were display ${ }^{3}$ typefaces as opposed to text ${ }^{4}$ faces. Slide 1 contained 3 columns while Slides $2 \& 5$ were single column and Slides $3 \& 4$ were single column 2 row slides. Slide 1 had a white background with a music note pattern, while Slides 2, $3 \& 4$ had an $80 \%$ grey background colour with a music note pattern and Slide 5 a flat $40 \%$ grey background. Hierarchy was created by use of Italic and Bold styles, however, this was used to create emphasis in the body of the slide when emphasis was required in heading text instead. A 3D text with a gradient and drop shadow were also used to create a powerful example of emphasis. This was the only text on Slide 2 of this Flipbook and thus did not cause readability

\footnotetext{
${ }^{2}$ Four of the five lessons are noted as having used a "flipbook" lesson. Flipbook is a term commonly associated with IWB presentations and describes the, often teacher created, presentations typically containing multiple "slides", "frames" or "pages". A flipbook as described in this study could be considered similar to a slideshow or Powerpoint.

${ }^{3}$ Display typefaces refer to typefaces that are decorative, ornate or designed such that they are intended for use at large sizes only and are appropriate for headings rather than body text.

${ }^{4}$ Text typefaces are typefaces that are designed with the intention of being used for the display of running text in the body or run of a text.
}

issues for other text on the slide, however, unity with the rest of the document was lost as this was the only time that this typographic treatment was used throughout the document.

\section{Observation 2 (refer to Table 2 on this page):}

Year 8 Music $^{5}$, Early Afternoon, Overcast

\section{Observation 2 Classroom layout/use:}

The IWB was positioned at the main focal point in the room with a mat area in front of the board that was able to comfortably accommodate the entire class. The teacher's desk was positioned next to the IWB. The light above the IWB was disconnected, there were a limited number of windows and no direct daylight was in contact with the board. Class began with students sitting on the mat in a semi circle facing the teacher positioned next to the IWB. Slide 1 was loaded before the students entered the room displaying an overview for the lesson.

Observation 2 Resource:

4 slide flipbook

\begin{tabular}{|c|c|c|c|}
\hline & & $\begin{array}{l}\text { Heading font } \\
\text { (text/background) }\end{array}$ & $\begin{array}{l}\text { Body font } \\
\text { (text/background) }\end{array}$ \\
\hline \multirow{3}{*}{$\frac{\bar{\Xi}}{\bar{\varpi}}$} & Col 1 & - & $\begin{array}{l}\text { Display } \\
\text { (black/red) }\end{array}$ \\
\hline & Col 2 & - & $\begin{array}{l}\text { Display } \\
\text { (red/80\% grey) }\end{array}$ \\
\hline & Col 3 & $\begin{array}{l}\text { Display } \\
\text { (red/40\% grey) }\end{array}$ & $\begin{array}{l}\text { Display Italics } \\
\text { (black } / 40 \% \text { grey) }\end{array}$ \\
\hline \multirow{2}{*}{ 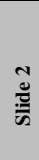 } & Row 1 & $\begin{array}{l}\text { Display } \\
\text { (black/80\% grey) }\end{array}$ & - \\
\hline & Row 2 & $\begin{array}{l}\text { Display Underlined } \\
\text { (black/80\% grey) }\end{array}$ & $\begin{array}{l}\text { Display } \\
\text { (black/80\% grey) }\end{array}$ \\
\hline$\stackrel{m}{\check{\pi}}$ & Col 1 & $\begin{array}{l}\text { Display } \\
\text { (40\% grey/black) }\end{array}$ & - \\
\hline$\stackrel{\Xi}{\varpi}$ & Col 1 & $\begin{array}{l}\text { Display } \\
\text { (black/40\% grey) }\end{array}$ & $\begin{array}{l}\text { Captions each with unique } \\
\text { typeface and colour }\end{array}$ \\
\hline
\end{tabular}

Table 2: Typographic Features of Observation 2

This flipbook contained multiple typefaces many of which were display typefaces as opposed to text faces. Slide 1 contained 3 columns while Slides 3 \& 4 were single column and Slide 2 was single column with 2 rows. Slide 1 had a white background with a music note pattern, while Slides $2 \& 3$ had a red background colour with a grey music note pattern and Slide 4 a flat $40 \%$ grey background with a red border on the slide. Underline was used successfully on 1 heading to create emphasis and hierarchy, while another slide used Italics to create hierarchy within the body of the text when it would have been more useful in the heading of this slide.

\footnotetext{
${ }^{5}$ This class was lead by the same teacher and in the same classroom as Observation 1 above. The content of the flipbook and the lesson plan was different as was the time of day and the effect on environmental considerations created by lesson timing in this same physical classroom produces an interesting longitudinal case study.
} 
Observation 4 Resource:

6 slide flipbook

Observation 3 (refer to Table 3 on this page):

Year 8 Reading, Mid Morning, Sunny

\section{Observation 3 Classroom layout/use:}

The IWB was positioned on a diagonal, facing $2 / 3 \mathrm{rds}$ of the classroom area. This was a small to moderate sized classroom with a small size mat, student tables cut into the mat area. The teacher's desk was positioned behind the IWB. The majority of the wall space consisted of windows with a large amount of sunlight coming into the classroom and falling onto the IWB. Class began with students sitting on the mat in front of the teacher who was positioned next to the IWB. Students were squashed into a small area, some sitting very close to the board and some between surrounding desks causing students to be situated behind table legs. Lights were turned off when the lesson began.

\section{Observation 3 Resource:}

Single slide with teacher interaction using the IWB pen

\begin{tabular}{|c|c|c|c|}
\hline & & $\begin{array}{l}\text { Heading font } \\
\text { (text/background) }\end{array}$ & $\begin{array}{l}\text { Body font } \\
\text { (text/background) }\end{array}$ \\
\hline 导 & Col 1 & $\begin{array}{l}\text { Display Bold } \\
\text { (black/lilac) }\end{array}$ & $\begin{array}{l}\text { Display } \\
\text { (black/lilac) }\end{array}$ \\
\hline
\end{tabular}

Table 3: Typographic Features of Observation 3

This flipbook contained a single display typeface used for both display and text settings. The single slide contained black text in a single column with a flat lilac background colour to the entire slide. The text did not have a separate background colour from the slide. Bold text was used to create hierarchy and emphasis in heading text.

\section{Observation 4 (refer to Table 4 on this page):}

Year 7 Written English, Mid Morning, Overcast/raining

\section{Observation 4 Classroom layout/use:}

The IWB was positioned at the head of the room with all furniture directed towards the board. A medium size mat was in front of the IWB and the teacher's desk positioned beside the board. Windows ran both lengths of the room. Class began with students sitting at their desks silent reading. Students remained at desks with lights on while the IWB was used.

\begin{tabular}{|c|c|c|c|}
\hline & & $\begin{array}{l}\text { Heading font } \\
\text { (text/background) }\end{array}$ & $\begin{array}{l}\text { Body font } \\
\text { (text/background) }\end{array}$ \\
\hline$\frac{\bar{v}}{\bar{\varpi}}$ & Col 1 & - & $\begin{array}{l}\text { Display Bold } \\
\text { (black/white) }\end{array}$ \\
\hline \multirow{3}{*}{$\stackrel{\cong}{\varpi ँ}$} & Col 1 & $\begin{array}{l}\text { Display Bold Underlined } \\
\text { (black/white) }\end{array}$ & - \\
\hline & Col 2 & $\begin{array}{l}\text { Display Bold Underlined } \\
\text { (black/white) }\end{array}$ & $\begin{array}{l}\text { Display } \\
\text { (black/white) }\end{array}$ \\
\hline & Col 3 & $\begin{array}{l}\text { Display Bold Underlined } \\
\text { (black/white) }\end{array}$ & - \\
\hline : & Col 1 & - & $\begin{array}{l}\text { Display } \\
\text { (black/light blue) }\end{array}$ \\
\hline : & Col 1 & - & $\begin{array}{l}\text { Text Bold Weight } \\
\text { (red/red) }\end{array}$ \\
\hline 营 & Col 1 & - & $\begin{array}{l}\text { Display } \\
\text { (forest green/light blue cloudy } \\
\text { sky pattern) }\end{array}$ \\
\hline :ँّ & Col 1 & - & $\begin{array}{l}\text { Display } \\
\text { (black/red) }\end{array}$ \\
\hline
\end{tabular}

Table 4: Typographic Features of Observation 4

This flipbook contained multiple typefaces all of which were display typefaces as opposed to text faces. Slide 2 contained 3 columns while Slides $1,3,4,5$ \& 6 were single column with blue strips of flat colour either side of the text columns. Slide 2 contained a pattern of pink circles of varying stroke widths with a darker pink backgound and the blue columns either side. Display typefaces were used in this document for both heading and body copy presentation, thus reducing the impact of these typefaces to create emphasis and hierarchy when reading. The teacher did however create added emphasis for headings through the use of Underline.

\section{Observation 5 (refer to Table 5 on follow page):} Year 7 Language, Mid Afternoon, Overcast/Raining

\section{Observation 5 Classroom layout/use:}

The IWB was positioned at the head of the room with all furniture directed towards the board. There was a medium to large size mat in front of IWB with the teacher's desk positioned beside the board. Windows ran both lengths of the room, with no windows directly behind board. Class began with students sitting at their desks facing the teacher and IWB. 
Observation 5 Resource:

3 slide flipbook

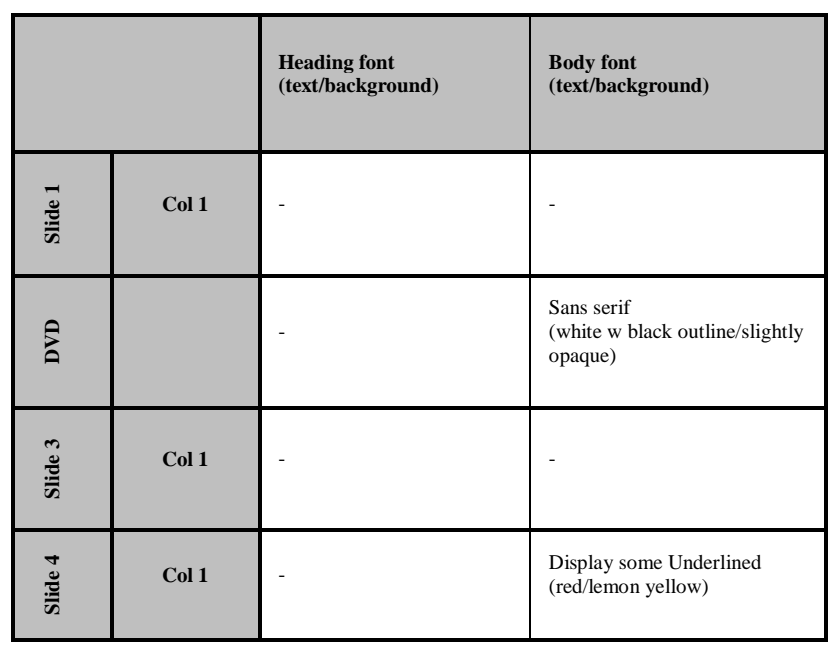

Table 5: Typographic Features of Observation 5

This flipbook contained 2 typefaces 1 display and 1 text face. Both typefaces were used for body copy text presentation. Slides $1,3 \& 4$ had a lemon yellow slide background with a light blue column either side, while the DVD contained video footage of animals. Very little hierarchy was created in this document as there was no slide that contained both heading and body text.

\section{OBSERVATION FINDINGS}

As Beeland (2002) discusses, IWB's have the potential to deliver instruction in a variety of ways, for a variety of learning styles and encourage student engagement through; visual learning with the use of text, graphics, animation and video; auditory learning with the use of sounds, words being pronounced, speeches, poems, listening, and music; and tactile learning with the ability for students to physically interact with the board. Interestingly, with these five observations there was no student interaction with the IWB. In each instance the children observed, read and discussed from either the mat, the desks or musical equipment, while the teacher controlled the flipbook transitions, played a DVD or utilised the IWB pen for annotation, highlighting and illustrating the lesson. Although outside the scope of this study, in a related study by this research team (Redacted for Review), it was observed that students at this school do engage in a range of interactive activities with the IWB in a range of curricula.

As the IWB has become a focal point of lessons, factors interfering with optimum projection have influenced the quality of projected material. Installation is also of consideration to ensure that lighting, glare and room composition do not hinder the ease of readability of a screen nor the angle of view, both of which can compromise clarity of the material for the student (Ramasoot \& Fotios, 2008; Winterbottom \& Wilkins, 2009). Similar to much of the literature, it was noted in our observations that classroom layouts were also not designed with Interactive Whiteboards in mind, as IWBs had been installed in classrooms developed for pre-IWB teaching resources. With this in mind, lighting was found to be one of the key influences on the clarity of material displayed on the Interactive Whiteboard at this school in early implementations. This school has recognised the impact of glare, and as such, blinds have been installed and traditional blackboard lights have been removed or disconnected. These proactive measures have resulted in no observable negative effects caused by environmental lighting during our study.

While Hughes \& Wilkins' (2002) research focused on 6-8 year old children and our study investigates 10-12 year old children, it was evident from our studies that when children were observed reading from the IWB from the mat position they were within the advised 3 meters of the board, however, when reading from their desks or music equipment some students would be outside of this prescribed optimal distance.

\section{Lesson Creation}

Results from Moss et al. (2007) indicated that a large percentage of teachers create their own resource material for IWB presentations, however teachers' lack of basic design knowledge can hinder the success of this material. It would seem, from our five observations, that all teachers at this school create their own flipcharts for use on the IWB. Only in one lesson was an additional video feature included in the lesson that navigated away from the teacher's self created resources. This again reinforces Moss et al's premise that teachers can be assisted to create more effective visual presentations with introduction to sound visual design principles.

\section{Typographic Display}

When designing reading material for children, it is critical that type and presentation decisions be made according to the reader's ability to visually identify information. Reading- or eye-paths ${ }^{6}$ need to be considered, and creating hierarchy to lead the reader through the complex information (visual and textural) is an important consideration when designing a page. Consideration of text size and clarity is also required to create legible flipbook presentations as IWB use entails reading from a distance.

\section{Typeface Selection}

Characteristics of a typeface suitable for children's reading are discussed in depth by several researchers (Burt, 1959; Walker \& Reynolds, 2000; Watts \& Nisbet, 1974). To ensure clear and readable text within a pixelbased environment, typeface selection for children's reading should ensure letterforms with distinctive variations between characters, along with glyphs with large $\mathrm{x}$-heights, and white space enclosed within the letterforms. The presentation of information on a screen is via a pixel based display which results in text that is not as clearly rendered due to the shape of letterforms being created using pixels as compared to vectors. With this in

\footnotetext{
${ }^{6}$ Reading-paths and eye-paths are terms used by typographic designers to describe the way a reader should scan or read a document (Kress, 2003). The correct use of these paths was not measured during this study, however expert review by the typographically trained observer has shown eye-path issues due to the structure of the text hierarchy.
} 
mind typeface choice and typographic setting requires special attention in this low resolution environment.

Typeface selection throughout the observed flipcharts varied from teacher to teacher. Typefaces can be categorized in two general systems; typefaces intended for display purposes and text typefaces. Display typefaces are intended for use for text such as headings, large print and illustration purposes; such typefaces are often ornate, decorative and illustrative in manner and work well at large sizes. Alternatively text typefaces, which are designed for ease of readability at a range of type sizes, are used effectively for continuous text such as sentences, paragraphs and a running body of text. In most instances it was found that teachers chose display typefaces for use as both headings and body copy and this had the potential to make smaller type difficult to read for the student sitting at a distance from the board.

It is good practice to create unity within a document and to ensure recognition of similar ideas through the consistent and repetitive use of typographic treatments including the use of the same typeface over multiple slides. Typeface selection for headings in observations 1 , 2 and 4 all showed a tendency to use a combination of display and text typefaces, whereas observations 3 and 5 displayed one common typeface used for both headings and body copy. Observation 4 combined five different typefaces in a range of display and text typefaces and styles throughout a six-slide flipbook. Due to the short nature of these presentation documents limiting of typefaces would be suggested to improve the unity of the information and the consistent presentation of similar information from one slide to the next.

Typeface choice can be an effective tool for creating hierarchy to help aid a child's reading, however the complexity of some of the typeface choices did have the ability to negatively affect reading in certain settings due to the use of highly decorative typefaces at small type sizes in body text.

Typeface selection is a factor that influences what is appropriate for minimum and maximum type size. Ornate typefaces will often need to be larger to ensure clarity, while crisp, clear typefaces will succeed in smaller sizes. Type size was often considered appropriate, however due to the use of ornate and decorative typefaces it would improve legibility in a number of the observed flipbooks to increase type size when expressive typefaces and varied typographic treatments are used.

\section{Typographic Space}

At times the space surrounding a block of text could have been increased due to the nature of the typeface selected and the size of the type or the size of the block of text. Type should be robust, clear and recognisable with generous spacing, leading and margins, in order for text to be readable and legible (Vanderschantz, 2008, 2009). Increasing the space around blocks of text will ensure effective reading paths. As the size of text and blocks of text increase the need for space around the blocks increases, thus in a reading from a distance situation such as the IWB spacing around text blocks becomes imperative to avoid crowding which is shown to cause readability issues.

\section{Typographic Colour}

A variety of colour combinations were evident in the lessons observed with three of the five flipcharts in our observation utilising traditional black text on a white background for body text. Headings consisted of a range of colours, along with multiple background treatments. Sufficient contrast between text and background colours was present in the majority of the flipcharts, however in a selection of slides, contrast lacked completely. This contradicts the advice of Vanderschantz et al. (2010) who showed that children's self correction and error rates for reading on screen, can be negatively affected by poor contrast and colour.

While background colours can create readability issues, so too can texture. Observation 4 combined a number of background textures with ornate typefaces which contributed to overly complicated reading environments in this low resolution environment.

Highlighting text with the pen highlight tool decreased readability due to a light yellow overlay, which gave the text a blurry appearance. Lighting conditions due to sunlight or room lighting also had a compounding negative effect when the pen was used to highlight. Another consideration when using the IWB pen was identified when a teacher using the IWB pen wrote additional notes along side the pre-prepared content. The pen's nib size was large which made the notes hard to read. The result was akin to writing with a dulled whiteboard marker on paper where smudging or ink bleed occurs.

\section{INTERVIEW FINDINGS}

Part two of this investigation revealed a range of student responses to questions regarding the typographic presentation of the lessons they attended.

In the interviews students provided specific reasons for why they preferred different typographic treatments over others. Students responded to 13 questions relating to typographic display, typeface selection, type size, typographic colour and typographic spacing as this related to the classes that had been observed.

\section{Typographic Display}

When questioned whether the typographic display was 'easy/hard' to read, students responded with a majority indicating 'easy'. Reasons explained by the students included the large size of text, their viewing position in relation to the IWB, and the colour of text and background being clear or having appropriate contrast.

With regard to text sizes for reading from a distance, one student commented that "it's not that big but I can just sit up closer" suggesting that instead of making the teacher aware of such visual difficulties caused by text presentation, perhaps students are instead likely to attempt to adjust their reading to suit the conditions of presented material rather than call attention to their difficulties. 


\section{Typeface Selection}

The controversial issue of whether serif or sans serif is better suited for children's reading produced complicated responses for the students. Seven of 17 students did not notice a difference between serif and sans serif typefaces, however a difference in the type of 'font' was noted. Ten of 17 students claimed to prefer a sans serif typeface, as it was easy to read and stands out. This indicates that students are aware of typeface selection and understand why they find some typefaces more readable than others.

Adding emphasis to headings and important sections of the text such as bold and italics had varying responses. Students preferred no use of italics in reading from the IWB's because it was often considered to make the text "blurry" and "hard to read". One student was able to identify that the use of italics in some typefaces was acceptable as these were clear and easy to read even as italics. Bolding content on the other hand was widely accepted as a positive emphasis, "having a line under a heading and also in bold makes it easy to separate the hearing (sic) from the text". This statement seems to indicate that use of emphasis and hierarchy in the creation of IWB material is required by the students in assisting with their understanding of the information being presented. While students indicated a preference for black on white text for body text, when asked if they like it when headings and key words are in colour, many students responded that they did. Contrasting this however, students tended to disliked the use of yellow for emphasis as this was discussed as being too light and difficult to read.

\section{Typographic Space}

When discussing the slides they had seen during their lessons, the students described considerations for typographic space, in terms of line and word spacing as well as space around text blocks, as fulfilled their reading requirements. One student stated that in relation to observation 1, the letters "were evenly spaced out and I didn't think the words were conjoined". It was noted from a number of the lessons that an increase in line spacing would help with reading, "when they're squeezed together I can't read it". Students were also able to identify that increased word spacing and line spacing was required on complex backgrounds or when low contrast was present for the text and background colour combinations.

\section{Typographic Colour}

When asked about typographic colour, black on white was generally considered to be the preferred text and background colour combination by the interviewees, they considered this to be the easiest to read. Students appeared to understand the need for contrast between text and background with one student stating, "having contrasting colors is the best because they're opposite, they make each other stand out". One student did discuss difficulties with the colour combinations of material presented in Observation 4 stating "its hard because I'm colour blind".

\section{DISCUSSION}

Expert review of the typographic quality of the presentation material, contrasted with user perception of the material has given insight into recommendations that can be made regarding the development of quality presentation material for children's reading from IWB.

With the increased use of technology, traditional use of text cannot simply be transferred from one medium to another. Consideration of text in relation to the target audience is important when creating digital resource material for children. The process of simply selecting text in another media, such as from handouts, printed books or the internet, and applying it to an IWB can result in poorly displayed and illegible text, and thus consideration of best practice for the display of typographic elements on IWB's needs to be accounted for.

The interview results clearly indicate that year 7-9 children (10-14 years old) have an educated understanding and personal preference of typographic factors within resource material. Students have a broad understanding of what readable type should look like, with specific reference to what they perceive to make text easy or hard to read. This aligns with findings by Walker (2005) who too was able to identify children's keen sense of typographic awareness. Students were found to have specific reasons as to why they did not like or could not read certain layouts of text.

\section{Recommendations}

From the observations and interviews it can be proposed that with typeface selection a clean, robust, easily read sans-serif typeface should be used and that an increase of line spacing will improve the clarity of the typographic display on screen. It was observed that for these screens, the use of italics should be used with caution as this can result in 'blurry' text that students described as hard to read. This was further emphasised by the students with 10 respondents having a preference for not using italics for headings or emphasis because "it can get a bit hard to read". Students also had a preference for sans serif typefaces that were "bolder and easier to read" which seemed contradictory to the ornate and decorative typefaces found on slides presented during the observations.

Typographic space is an important consideration for the display of readable and legible type. Improving teachers' sensitivity for spacing of typography and visual features of the layout will aid in the ability for children to read effectively from interactive whiteboards due to the creation of effective eye paths and visual and typographic hierarchy. Loose space between lines of text was a factor that students identified as assisting in creating type that they perceived as easily readable. This is interesting because interlinear spacing for adults reading has been studied in the literature, however user preference for loose or tight interlinear spacing is not evident. Reynolds \& Walker (2004) identify preferences in horizontal spacing, but not vertical spacing for children reading in print. 
Another recurring sentiment from the students interviewed found a strong preference for traditional black text on white as a colour combination, however, this combination was used infrequently in the observed lessons. This is similar to the findings of Vanderschantz et al. (2010) who found that their second largest group of respondents considered Black on White text to be their preferred reading condition, while the largest group of respondents in that study had no preference. In that same study it was found that 58 of 61 students claimed that Black on White was the most common colour combination that they read, this may explain this preference. Due to the uncontrolled natural lighting conditions in some classrooms contrast between foreground (text) and background colour, such as black on white proposed by the students, will also help with the legibility of type.

As has been seen in other studies, classroom layouts were not designed with the installation of IWB in mind, and therefore lighting was found to be one of the key influences on the clarity of IWB resource material. The installation of blinds and ensuring fluorescent lighting is turned off when the IWB is in use will increase the visual contrast of IWB content. Observations at this school found no direct light casts were falling on the whiteboards and this will have had a positive effect on the readability of this material.

The lack of consideration for classroom layout was also noticeable with the distance students were sitting from the IWB. Hughes et al. (2002) suggests that a child of 6-8 years should have a reading distance of a maximum of $10 \mathrm{ft}(3 \mathrm{~m})$. In four of the five observed lessons, some or all of the students were required to read the IWB from a distance beyond this recommended distance. The factor of distance compounded with less than ideal typographic conditions, such as display typefaces being used for body copy at small sizes could have a significant effect on students reading. As indicated by one of the students in this study, students may be unwilling to alert the teacher to the difficulty they may be having with reading this content.

\section{Conclusions \& Future Work}

This research has shown that students in NZ middle schools understand the typographic conditions that effect material presented to them in the classroom. We also believe that as is discussed by Moss et al. (2007) educating teachers in the effective use of typographic display, typographic space, typographic colour and typeface selection will assist them to improve the readability and legibility of reading material presented on IWB through effective eye- and reading-paths. A starting point for such recommendations for effective typographic presentation on IWB would be the considerations and preferences raised by students in our study. These recommendations would be; the use of large, easily read sans-serif typefaces and using high contrast foreground and background colours as students felt that these factors made the text easier to read. Limited use of decorative typefaces and italics is also recommended, as these were perceived by the students to make text difficult to read.
Further studies will endeavor to investigate teachers decision making when presenting text for childrens' onscreen viewing, as well as measuring eye paths with reading material on IWB and testing of prototypical typographic presentations for children's reading on IWB.

\section{REFERENCES}

Beeland, W. D. (2002). Student engagement, visual learning and technology: Can interactive whiteboards help. Annual Conference of the Association of Information Technology for Teaching Education.

Burt, C. (1959). A Psychological Study of Typography. London: Cambridge University Press.

Dillon, A. (2004). Designing usable electronic text (2nd ed.). USA: CRC Press LLC.

Huey, E. B. (1908). The Psychology and Pedagogy of Reading with a Review of the History of Reading and Writing and of Methods, Texts, and Hygiene in Reading. The Macmillan company.

Hughes, L. E., \& Wilkins, A. J. (2002). Reading at a distance: Implications for the design of text in children's big books. British Journal of Educational Psychology, 72(2), 213-226.

Kress, G. (2003). Literacy in the New Media Age. Routledge.

Legge, G. E., Pelli, D. G., Rubin, G. S., \& Schleske, M. (1985). Psychophysics of reading--I. Normal vision. Vision Research, 25(2), 239.

Lupton, E. (2004). Thinking with Type. A critical guide for designers, writers, editors, \& students. New York: Princeton Architectural Press.

Morison, S. (1936). First principles of typography. Macmillan.

Moseley, D., Higgins, S., Bramald, R., Hardman, F., Miller, J., Mroz, M., Tse, H., et al. (1999). Ways forward with ICT: Effective Pedagogy Using Information and Communications Technology for Literacy and Numeracy in Primary Schools.

Moss, G., Jewitt, C., Levacic, R., Armstrong, V., Cardini, A., \& Castle, F. (2007). The interactive whiteboards, pedagogy and pupil performance evaluation: An evaluation of the schools whiteboard expansion (SWE) project: London challenge. DfES.

Ramasoot, T., \& Fotios, S. (2008). Lighting for the Classrooms of the Future. Electronic Classrooms: a New Challenge for School Lighting Guidance. BalkanLight.

Rayner, K. (1998). Eye Movements in Reading and Information Processing: 20 Years of Research. Psychological Bulletin, 124(3), 372-422.

Reynolds, L., \& Walker, S. (2004). 'You can't see what the words say': word spacing and letter spacing in children's reading books. Journal of Research in Reading, 27(1), 87-98.

Tinker, M. A. (1963). Legibility of print. Ames, Iowa, USA: Iowa State University Press.

Vanderschantz, N. (2008). Text Spacing Considerations for Children's On-Screen Reading. Proceedings of World Conference on Educational Multimedia, Hypermedia and Telecommunications 2008 (pp. 16091616). USA: AACE. 
Vanderschantz, N. (2009). Greater Understanding of Spacing Needs for Children's Eye Movements during On-Screen Reading is Required. Proceedings of World Conference on Educational Multimedia, Hypermedia and Telecommunications 2009 (pp. 807-813). USA: AACE.

Vanderschantz, N., Timpany, C., Whitehead, D., \& Carss, W. (2010). A Small Scale Study into the Effect that Text \& Background Colour has on Processing and SelfCorrection Rates for Childrens' On-Screen Reading. International Journal of the Book, 8(1).
Walker, S. (2005). The songs the letters sing: typography and children's reading. Reading: National Centre for Language and Literacy.

Walker, S., \& Reynolds, L. (2000). Screen design for children's reading: some key issues. Journal of Research in Reading, 23(2), 224-234. doi:10.1111/1467-9817.00116

Watts, L., \& Nisbet, J. (1974). Legibility in children's books : a review of research. Windsor: NFER.

Winterbottom, M., \& Wilkins, A. (2009). Lighting and discomfort in the classroom. Journal of Environmental Psychology, 29(1), 63-75. 